\begin{tabular}{|l|l|l||}
\hline \multicolumn{2}{|c|}{ PublisherInfo } \\
\hline \hline PublisherName & $:$ & BioMed Central \\
\hline \hline PublisherLocation & $:$ & London \\
\hline \hline PublisherImprintName & $:$ & BioMed Central \\
\hline \hline
\end{tabular}

\title{
Ang1 in breast cancer
}

\begin{tabular}{|l|l|l||}
\hline \multicolumn{2}{|c|}{ ArticleInfo } \\
\hline \hline ArticleID & $:$ & 3756 \\
\hline \hline ArticleDOI & $:$ & $10.1186 /$ bcr-2000-66719 \\
\hline \hline ArticleCitationID & $:$ & 66719 \\
\hline \hline ArticleSequenceNumber & $:$ & 28 \\
\hline \hline ArticleCategory & $:$ & Paper Report \\
\hline \hline ArticleFirstPage & $:$ & 1 \\
\hline \hline ArticleLastPage & $:$ & 4 \\
\hline \hline & & RegistrationDate : 2000-11-30 $\quad: \quad 2000-11-30$ \\
\hline ArticleHistory & $:$ & OnlineDate \\
\hline \hline ArticleCopyright & $:$ & Current Science Ltd2000 \\
\hline \hline ArticleGrants & $:$ & \\
\hline \hline ArticleContext & $:$ & 1305833 \\
\hline \hline
\end{tabular}


Aff1 Molecular Medicine Unit, University of Leeds, UK

\section{Keywords}

Angiogenesis, angiopoietin, gene expression, neovascularisation, tumourigenesis

\section{Introduction}

Angiogenesis involves vascular remodelling, either by formation of new blood vessels or regression of superfluous vessels. In the normal adult there is relatively little angiogenesis, but it is well documented that blood vessel growth is required for tumour growth. Although vascular endothelial growth factor (VEGF) is probably the best characterised angiogenic factor, Ang1 has been described more recently. Ang1 is a ligand for the Tie2 receptor which is located in the vasculature. Transgenic studies show that Ang1 is necessary for the development of embryonic vasculature. Overexpression of Ang1 in the skin results in increased number and branching of dermal vessels. Studies in vitro show Ang1 stabilises mature vasculature by preventing endothelial cell apoptosis. Thus, Ang1 has a physiological role as an angiogenic promoter.

\section{Aims}

To investigate whether Ang1 serves as a proangiogenic factor in breast tumours using in vitro and in vivo approaches.

\section{Comments}

The angiopoietins are a recently identifed family of angiogenic factors that play a crucial role in vascular maintenance. Here, it is demonstrated that angiopoietin 1 (Ang1), which in previous work has shown proangiogenic effects, is expressed only at very low levels in clinical breast samples. Interestingly, when overexpressed in breast cancer xenografts, it had inhibitory effects on tumour growth. Ang 1 is structurally related to Ang2 and both are ligands for the Tie2 receptor to which they bind with similar affinity. Ang2, however, appears to be a naturally-occurring antagonist of Ang1 since 
it specifically inhibits Ang1-dependent phosphorylation of Tie2. Therefore, the role of Ang2 needs to be considered in the context of this model system.

\section{Methods}

Ang1 expression was analysed by RT-PCR in a range of breast cancer cell lines and in clinical material following laser-capture microdissection. Sections were immunostained with Tie2 and von Willebrand factor (vWF) to identify areas of high vessel density. Derivative cell lines of MCF-7 were used. MCPX, a subline of ML-20 (MCF-7 derivative) was derived by transfection with $\beta$-galactosidase and $\alpha-18$ was derived from ML-20 by transfection with fibroblast growth factor (FGF)-1. Cells were transfected with full length human Ang1 cDNA and medium collected for western blot analysis. The ability of Ang1 to bind to Tie2 was determined by BIAcore analysis. Tie2 phosphorylation was measured in Tie2-transfected fibroblasts. Tumourigenicity assays were performed using 4-6 week old female NCr nu/nu nude mice inoculated subcutaneously with FGF-1 transfected MCF-7 xenografts.

\section{Results}

Ang1 expression was detected in 9 out of 19 breast cancer cell lines but only in 3 out of 21 breast tumours and 0 out of 9 normal breast tissue samples, despite expression of Tie 2 on microvessels adjacent to the tumour and a strong correlation with vWF expression. Transfection of the oestrogendependent, poorly angiogenic and weakly tumourigenic MCPX and $\alpha-18$ cell lines with Ang1 caused the release of biologically active Ang 1 into the culture medium, ranging from $156-820 \mathrm{ng} / \mathrm{ml}$. This was capable of inducing Tie 2 tyrosine phosphorylation.Ang1 overexpressing MCPX cells grew well as xenografts but compared to vector controls, showed a decreased growth rate. Similar effects were observed with xenografts of FGF-1 and Ang1 co-transfected $\alpha-18$ cells.

\section{Discussion}

Ang1 was rarely expressed in breast tumours, despite the abundant expression of Tie 2 in vessels adjacent to the tumour. Overexpression of Ang1 not only failed to stimulate xenograft growth, but Ang1 transfectants showed reduced growth rates. In contrast to its previous proangiogenic role, it would appear that in this model system, Ang1 is an inhibitor of angiogenesis. The stabilising effect of Ang1 on the vasculature (which would be a negative selective effect in tumour development) may lead to its downregulation in tumours. 


\section{References}

1. Hayes AJ, Huang W-Q, Maisonpierre PC, Liu A, Kern FG, Lippman ME, McLeskey SW, Li L-Y: Expression and function of Ang1 in breast cancer. Br J Cancer. 2000, 83: 1154-1160. 